\title{
Visual Population Receptive Fields in People with Schizophrenia Have Reduced Inhibitory Surrounds
}

\author{
Elaine J. Anderson, ${ }^{1,2,3}$ Marc S. Tibber, ${ }^{1}$ D. Sam Schwarzkopf, ${ }^{2,4}$ Sukhwinder S. Shergill, ${ }^{5,6}$ Emilio Fernandez-Egea, ${ }^{7,8}$ \\ (CGeraint Rees, ${ }^{2,3}$ and $\mathbb{Q}$ Steven C. Dakin ${ }^{1,9}$ \\ ${ }^{1}$ Institute of Ophthalmology, ${ }^{2}$ Institute of Cognitive Neuroscience, ${ }^{3}$ Wellcome Trust Centre for Neuroimaging, and ${ }^{4}$ Experimental Psychology, University College \\ London, London, United Kingdom, ${ }^{5}$ Department of Psychosis Studies, Institute of Psychiatry, Psychology and Neuroscience, King's College London, London, \\ United Kingdom, ${ }^{6}$ South London and Maudsley National Health Service Foundation Trust, London, United Kingdom, ${ }^{7}$ Clozapine Clinic, Cambridgeshire and \\ Peterborough National Health Service Foundation Trust, and ${ }^{8}$ Department of Psychiatry, Behavioural and Clinical Neuroscience Institute, University of Cambridge, \\ Cambridge, United Kingdom, and ${ }^{9}$ School of Optometry and Vision Science, University of Auckland, Auckland, New Zealand
}

People with schizophrenia (SZ) experience abnormal visual perception on a range of visual tasks, which have been linked to abnormal synaptic transmission and an imbalance between cortical excitation and inhibition. However, differences in the underlying architecture of visual cortex neurons, which might explain these visual anomalies, have yet to be reported in vivo. Here, we probed the neural basis of these deficits using $\mathrm{fMRI}$ and population receptive field ( $\mathrm{pRF}$ ) mapping to infer properties of visually responsive neurons in people with SZ. We employed a difference-of-Gaussian model to capture the center-surround configuration of the pRF, providing critical information about the spatial scale of the pRFs inhibitory surround. Our analysis reveals that $\mathrm{SZ}$ is associated with reduced pRF size in early retinotopic visual cortex, as well as a reduction in size and depth of the inhibitory surround in V1, V2, and V4. We consider how reduced inhibition might explain the diverse range of visual deficits reported in SZ.

Key words: fMRI; perception; pRF; schizophrenia; surround suppression; visual cortex

Significance Statement

People with schizophrenia (SZ) experience abnormal perception on a range of visual tasks, which has been linked to abnormal synaptic transmission and an imbalance between cortical excitation/inhibition. However, associated differences in the functional architecture of visual cortex neurons have yet to be reported in vivo. We used fMRI and population receptive field (pRF) mapping to demonstrate that the fine-grained functional architecture of visual cortex in people with SZ differs from unaffected controls. SZ is associated with reduced pRF size in early retinotopic visual cortex largely due to reduced inhibitory surrounds. An imbalance between cortical excitation and inhibition could drive such a change in the center-surround pRF configuration and ultimately explain the range of visual deficits experienced in SZ.

\section{Introduction}

People with schizophrenia (SZ) experience abnormal visual perception on a range of visual tasks (Butler et al., 2008), including

Received Sept. 23, 2015; revised 0ct. 22, 2016; accepted Nov. 15, 2016.

Author contributions: E.J.A., M.S.T., D.S.S., S.S.S., G.R., and S.C.D. designed research; E.J.A., M.S.T., D.S.S., and S.S.S. performed research; E.F.-E. contributed unpublished reagents/analytic tools; E.J.A. and D.S.S. analyzed data; E.J.A., D.S.S., G.R., and S.C.D. wrote the paper.

This work was supported by the Wellcome Trust (E.J.A., G.R., S.C.D.), the European Research Council (Starting Grant 310829 to D.S.S. and Consolidator Grant 311686 to S.S.S.), and the National Institute for Health Research (NIHR) Biomedical Research Centre at South London and Maudsley NHS Foundation Trust and King's College London (S.S.S.). The Wellcome Trust Centre for Neuroimaging is supported by core funding from the Wellcome Trust (Grant 091593/Z/10/Z). We thank two anonymous reviewers for their valuable comments.

The authors declare no competing financial interests.

Correspondence should be addressed to Dr. Elaine Anderson, UCL Institute of Ophthalmology, 11-43 Bath Street, London EC1V 9EL, UK. E-mail: e.anderson@ucl.ac.uk.

DOI:10.1523/JNEUROSCI.3620-15.2016 reduced contrast sensitivity (Slaghuis, 1998) poor orientation discrimination (Tibber et al., 2015), impaired motion processing (Chen et al., 2004; Kim et al., 2006), and anomalous global processing such as detecting contours embedded in noise (Silverstein et al., 2000; Uhlhaas et al., 2006b; Robol et al., 2013). These findings have been interpreted as a general failure of integration, such that objects and scenes are experienced as fragmented parts rather than coherent wholes (Silverstein and Keane, 2011).

People with SZ are also less influenced by visual context such that their visual discrimination performance is less affected by the presence of disruptive (Tadin et al., 2006) or facilitatory (Must et Creative Commons Attribution 4.0 International, which permits unrestricted use, distribution and reproduction in any medium provided that the original work is properly attributed. 
Table 1. Clinical data for the full group of 13 people with schizophrenia

\begin{tabular}{|c|c|c|c|c|c|c|c|c|c|c|c|c|}
\hline Diagnosis & Sex & Age & Med & Type & Dose & IQ & tPANSS & tPSS & tNSS & tGSS & tDIS & $\overline{D I S}$ \\
\hline$S Z$ & M & 39 & Aripiprazole & 2nd & 133 & 95 & 44 & 9 & 12 & 23 & 9 & 1 \\
\hline$S Z$ & $\mathrm{~F}$ & 38 & Clozapine & 2nd & 800 & 100 & 100 & 20 & 28 & 52 & 15 & 4 \\
\hline PS & M & 42 & Clozapine & 2nd & 750 & 101 & 59 & 13 & 14 & 32 & 9 & 1 \\
\hline PS & M & 53 & Clozapine & 2nd & 1000 & 89 & 40 & 12 & 9 & 19 & 8 & 2 \\
\hline$S Z$ & $M$ & 36 & Olanzapine & 2nd & 200 & 111 & 42 & 7 & 14 & 21 & 8 & 1 \\
\hline PS & M & 28 & Pipotiazine & 1st & 200 & 101 & 64 & 11 & 23 & 30 & 14 & 3 \\
\hline$S Z$ & M & 53 & - & - & 150 & 95 & 73 & 16 & 25 & 32 & 11 & 1 \\
\hline$S Z$ & $M$ & 31 & Clozapine & 2nd & 800 & 100 & 63 & 13 & 18 & 32 & 10 & 1 \\
\hline PS & $\mathrm{F}$ & 43 & Quetiapine & 2nd & 1400 & 117 & 55 & 12 & 17 & 26 & 11 & 2 \\
\hline PS & M & 30 & Clozapine & 2nd & 1000 & 106 & 58 & 12 & 20 & 26 & 9 & 1 \\
\hline PS & $M$ & 28 & Clozapine & 2nd & 500 & 84 & 53 & 9 & 20 & 24 & 14 & 3 \\
\hline PS & $M$ & 49 & Clozapine & 2nd & 1200 & 86 & 63 & 15 & 16 & 32 & 9 & 3 \\
\hline PS & M & 50 & Olanzapine & 2nd & 200 & 89 & 47 & 7 & 17 & 23 & 10 & 1 \\
\hline Mean & - & 40 & - & - & 641 & 98 & 58.5 & 12 & 17.9 & 28.6 & 10.5 & 1.8 \\
\hline SD & - & 9.2 & - & - & 438.9 & 9.7 & 15.8 & 3.7 & 5.3 & 8.4 & 2.4 & 1.1 \\
\hline
\end{tabular}

The following information is provided: diagnosis ( $S Z$ = schizophrenia; $P S=$ paranoid schizophrenia), medication (Med), medication type (1st = first-generation antipsychotic; 2 nd = second-generation antispsychotic), medication dose (chlorpromazine equivalent in mg/d), intelligence quotient (IQ/NART score), total scores for the entire PANSS test (tPANSS), total scores for the positive symptoms of the PANSS test (tPSS), total scores for the negative symptoms of the PANSS test (tNSS), total scores for the general symptoms of the PANSS test (tGSS), scores on a cognitive factor, which overlaps heavily with the concept of disorganization syndrome (tDIS), and scores for item P2 on the PANSS test, "conceptual disorganization" (DIS).

al., 2004) surrounds and they experience weaker illusions based on visual context compared with unaffected observers (Dakin et al., 2005; Robol et al., 2013; Tibber et al., 2013; Yang et al., 2013). For example, in the "contrast-contrast" illusion, a typical observer would perceive a target patch to be of higher contrast when placed in isolation compared with when embedded within a high-contrast surround (Chubb et al., 1989). People with SZ experience weaker contrast-contrast effects that result in more accurate judgements of target contrast (Dakin et al., 2005; Tibber et al., 2013; Yang et al., 2013; Schallmo et al., 2015), although effect size seems to depend on symptom severity (Barch et al., 2012). These findings suggest that a specific neural mechanism differs in this group, rather than poor comprehension or performance of the task. Such "surround suppression" is thought to be mediated by the inhibition of a neuron's response to a stimulus by the pooled activity of cells in the surrounding cortex (Cavanaugh et al., 2002). For simple grating stimuli, this has been shown to operate within V1, V2, and V3, with the strongest effects in V2 and V3 (Zenger-Landolt and Heeger, 2003).

Tests of visual perception are becoming popular for developing models of impaired neural processing in SZ (Silverstein and Keane, 2011; Metzner et al., 2014; Phillips et al., 2015; Silverstein et al., 2015). For example, the neurodevelopmental hypothesis posits that SZ results from disturbed neural development (Murray and Lewis, 1987; Weinberger, 1987) that could affect the neural architecture of visual cortex (with knock-on effects for perception). Perceptual deficits in SZ have often been linked to a selective loss of large magnocellular (M-cell) neurons (Butler et al., 2005; Martínez et al., 2008), with correspondingly large receptive fields that respond preferentially to coarse-scale dynamic image structure. Their loss could account for poor sensitivity to low SFs (Butler et al., 2001) and impaired motion processing in SZ (O’Donnell et al., 1996; Chen et al., 2004; Kim et al., 2006). Consistent with this, postmortem studies have indicated a reduction in mean neuronal somal size (Rajkowska et al., 1998), but also increased neuronal density (Selemon et al., 1995) and a reduction in neuron number, volume, and surface area of V1 in SZ (Dorph-Petersen et al., 2007).

To date, in vivo neuroimaging has provided mixed reports on whether the magnitude of responses and/or the topography of early visual areas differ between patients with SZ and controls
(Martínez et al., 2008; Wynn et al., 2008). Wynn et al. (2008) found good spatial overlap of normalized retinotopic maps in early visual areas in people with SZ and healthy controls and no difference in peak response amplitude, whereas Martínez et al. (2008) found the cortical extent of V1 and V2 to be 15\% lower in SZ. However, both of these studies determined functional properties of the visual cortex at a macroscopic spatial scale (e.g., retinotopic maps). Here, we sought to clarify whether the finegrained functional architecture of visual cortex in people with SZ differs from unaffected controls using $\mathrm{fMRI}$ and population receptive field (pRF) mapping (Wandell et al., 2007; Dumoulin and Wandell, 2008; Wandell and Winawer, 2015) to estimate the size (width) of pRFs in retinotopic visual cortex. In addition, by using a difference of Gaussian (DoG) model, we probed the spatial scale of the pRFs inhibitory surround (Zuiderbaan et al., 2012). First, we hypothesized that, if SZ is associated with a selective loss of M-cells, then we would observe a bias toward smaller pRF size in patients compared with controls. Second, we hypothesized that the centersurround relationship would differ in people with SZ compared with controls such that the inhibitory surround would be reduced (in size and/or depth), providing a possible explanation for the reduced surround suppression observed in this group.

\section{Materials and Methods}

Participants. Eighteen participants with SZ (2 female) and 14 healthy control participants ( 6 female) gave informed written consent to take part in this study. Participants with SZ were recruited from outpatients at the Institute of Psychiatry, Kings College London, and the Clozapine Clinic, Cambridgeshire and Peterborough NHS Foundation Trust. All were diagnosed with SZ according to DSM-IV-R criteria by an experienced psychiatrist. Of the 18 patients tested, 12 were diagnosed with paranoid SZ and the remaining six did not fall into any specific subcategory. Participants symptom severity was assessed using the Positive and Negative Symptoms Scale (PANSS) (Kay et al., 1987) within 1 week of testing. The National Adult Reading Test (NART) was used to estimate IQ in all participants (Nelson and Willison, 1991).

Three participants with SZ were unable to maintain adequate head and eye stability during the MRI scans and two were unable to perform the central fixation task, so their data have not been included. For the remaining 13 patients and 14 controls, there was no significant difference in age (patients 40 years \pm 9.2 , controls 33.9 years $\pm 7.5: t_{(25)}=1.881$, $p=0.072$ ); however, there was a significant difference in IQ (patients $98 \pm 9.7$, controls $111.7 \pm 8.9: t_{(25)}=-3.825, p=0.001$; see Table 1 for 

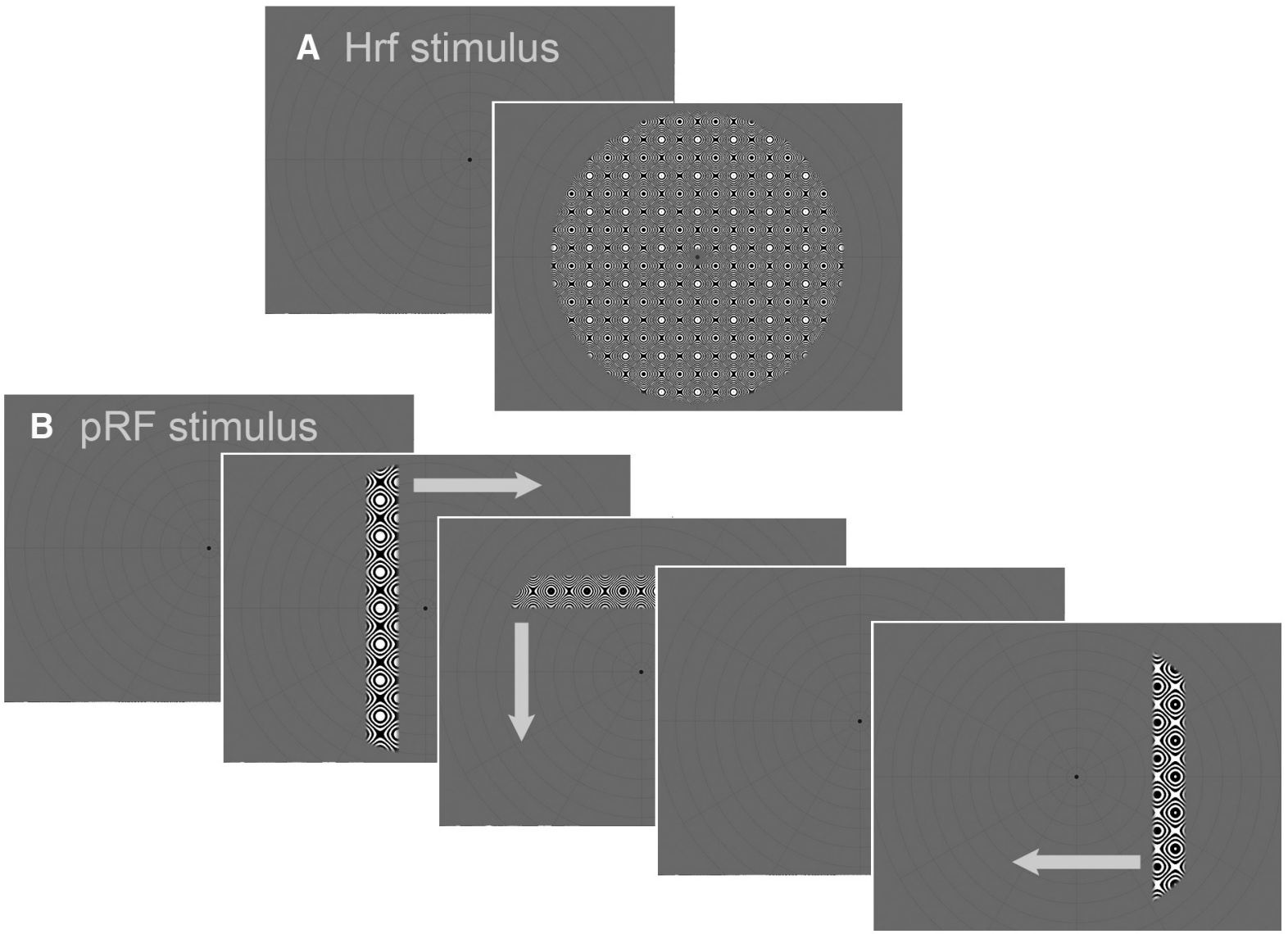

Figure 1. Illustration of the stimuli used for modeling the HRF $(\boldsymbol{A})$ and pRF mapping $(\boldsymbol{B})$. In $\boldsymbol{A}$, the full field rippling stimulus was presented briefly for $2.55 \mathrm{~s}$ ( 1 volume) and the background fixation screen then reappeared for $28.05 \mathrm{~s}$ (11 volumes) before another full-field stimulus was presented again. This sequence was repeated 10 times per HRF scan run. In $\boldsymbol{B}$, each image represents one volume of each block type. Only four (out of six) blocks are represented here. For each orientation/direction, the bar aperture traversed the entire field in 24 discrete steps. The third and sixth block always contained a blank period. The order of sweep directions varied between scan runs.

patient demographics). The main results presented in Figures 3 and 4 are for this larger, unmatched group; however, given the link between IQ and strength of perceptual suppression (Melnick et al., 2013), we also provide statistical results for a smaller IQ-/age-matched group $(n=10$; age $t_{(18)}=2.021, p=0.058$, IQ $\left.t_{(18)}=1.973, p=0.064\right)$. The results for the latter group strengthen the effects seen in the larger unmatched group. All procedures were approved by the University College London Research Ethics Committee. All participants had normal or corrected-to normal visual acuity.

$f M R I$ stimuli and $p R F$ mapping. Each participant underwent five functional scan runs: four runs for pRF mapping and one run to estimate the hemodynamic response function (HRF). For all of these, a high-contrast dynamic "ripple" stimulus (Fig. 1A) was used to maximize the visual response (for further details of the stimulus, see Schwarzkopf et al. (2014)). Images were projected onto a rear-mounted screen, which was viewed via a mirror system mounted on the head coil. In this position, the full-aperture stimulus covered a circular region that subtended $9^{\circ}$ of visual angle around fixation. All stimuli were generated in MATLAB R2012a (The MathWorks) and displayed using Psychtoolbox-3 (Brainard, 1997).

For the mapping runs, participants fixated centrally while passively viewing a moving bar aperture that exposed the dynamic rippling stimulus (Fig. $1 B)$. The bar aperture subtended $1.5^{\circ}$ and traversed the visual field in 24 discrete steps of $0.75^{\circ}$ ( 1 step per fMRI image acquired). The bar was oriented horizontally or vertically and could move in either direction across the screen, making four possible sweep orientations/directions in total. Each scan run contained four sweeps of the bar (one for each orientation/direction) and two blank periods. The order of the bar orientation/direction varied across scan sessions, but the blank periods always came after the second and fourth sweep. The bar aperture was bound by the outer edge of the circular ripple pattern, where the contrast of the ripple was linearly ramped down to zero over $0.28^{\circ}$. For the HRF measurement, the full-aperture ripple image was briefly presented for 1 volume $(2.55 \mathrm{~s})$, followed by a long blank period of 11 volumes $(28.05 \mathrm{~s}$ ) (Fig. $1 A$ ). This sequence was repeated 10 times to complete the HRF scan run.

Participants were required to maintain central fixation throughout the pRF mapping and HRF scan runs and simultaneously perform a central fixation task: a central blue circle (diameter $0.23^{\circ}$ ) intermittently changed color to magenta for $200 \mathrm{~ms}$. Participants indicated by key press every time they detected a color change. In addition, eye movements were monitored throughout the scan run using an Eyelink 1000 MRIcompatible eye tracker (http://www.sr-research.com). To further facilitate central fixation, a low-contrast radial pattern was superimposed over the entire stimulus area. This comprised 12 radial lines extending from just outside the fixation dot and 11 concentric rings centered on fixation increasing in radius with eccentricity.

Data acquisition and scan timing. MRI data were acquired using a Siemens 3T TIM-Trio scanner using a 32-channel head coil. For the functional scan runs, a high-resolution EPI sequence $(2.3 \mathrm{~mm}$ isotropic, interleaved slice order, $96 \times 96$ matrix, slice acquisition time $85 \mathrm{~ms}$, TE $37 \mathrm{~ms}$ ) was used to acquire 30 near axial slices positioned to optimize coverage of the occipital lobe. The front of the head coil was removed for these scans to allow participants an unrestricted view of the screen, leaving 20 receiving channels. To assess the homogeneity of the magnetic field with the front of the head coil removed, we acquired $B_{0}$ field maps after the functional scan runs (double-echo FLASH sequence, short TE $10 \mathrm{~ms}$, long TE $12.46 \mathrm{~ms}, 3 \times 3 \times 2 \mathrm{~mm}$ resolution, $1 \mathrm{~mm}$ gap). We also acquired two T1-weighted structural images, one with the front of the coil removed (MPRAGE, $1 \mathrm{~mm}$ isotropic voxels, 176 sagittal slices, $256 \times 215$ matrix, TE $2.97 \mathrm{~ms}$, TR $1900 \mathrm{~ms}$ ), which was used as an intermediate step in coregistering functional data to a second, high-resolution anatomical image acquired with the full head coil (3D MDEFT, $1 \mathrm{~mm}$ isotropic voxels, 176 
sagittal slices, $256 \times 240$ matrix, TE $2.48 \mathrm{~ms}$, TR $7.92 \mathrm{~ms}$, TI $910 \mathrm{~ms})$. The latter was used for segmentation and cortical reconstruction.

For each pRF mapping scan run, we acquired 148 volumes using a TR of $2.55 \mathrm{~s}$ (total duration $6 \mathrm{~min} 17 \mathrm{~s}$ ). This included four "dummy" scans acquired at the beginning of each run to allow the brain to reach steadystate magnetization. The central blue dot was presented during the dummy scans and central fixation maintained before the first mapping stimulus appeared. Each sweep of the traversing bar stimulus or blank period lasted $61.2 \mathrm{~s}$, during which time we acquired 24 volume images. For the HRF scan run, we acquired 124 volumes (including 4 dummy scans) using a TR of $2.55 \mathrm{~s}$ (total duration $5 \mathrm{~min} 16 \mathrm{~s}$ ).

MRI data analysis. All functional data were preprocessed using SPM8 (http://www.fil.ion.ucl.ac.uk). All functional images were intensity bias corrected using in-house software to aid automated preprocessing of the images. The dummy volumes were then discarded and the remaining images from the mapping and HRF scans were realigned and unwarped (using the $B_{0}$ field maps to correct any image distortion) and coregistered to the individual's high-resolution T1 structural image acquired with the coil on, using the additional MPRAGE structural image acquired with the front of the head coil off as an intermediate step.

Freesurfer software (http://surfer.nmr.mgh.harvard.edu, version 5.0.0) was used to create $3 \mathrm{D}$ surface meshes of both cortical hemisphere for each individual, one for the boundary between gray and white matter and one for the outer pial boundary of the white matter. The cortical surfaces were then inflated.

All further analyses were performed using a custom MATLAB toolbox developed in-house (http://dx.doi.org/10.6084/m9.figshare.1344765) for pRF analysis and for projecting data onto the cortical surface. Data analysis was restricted to a region including the occipital, posterior temporal, and posterior parietal areas defined manually for each individual. To project functional data onto the smoothed gray/white matter surface, we determined the point midway between the gray/white and pial surfaces for each vertex on the gray/white matter boundary and used this gray matter voxel to create a functional time series for each vertex for all mapping and HRF scan runs. Linear detrending and $z$-score normalization were applied to these time series.

To estimate each individual's HRF, we averaged the signal evoked by the 10 photic bursts of the HRF scan. Outliers greater than \pm 1.5 SDs from the mean were excluded from the time series of each vertex. Analysis was restricted to only visually active vertices, defined by a response $>1$ SEM averaged over the first 5 scans after each burst. A double-gamma function was then fitted to the averaged stimulus evoked response to estimate the HRF for each hemisphere independently. There were four free parameters: the latency of the peak response and the undershoot, the peak amplitude, and the ratio of the peak and undershoot amplitudes.

For the pRF analysis, we used a forward modeling approach similar to that described by Dumoulin and Wandell (2008) to estimate the pRF parameters for each vertex independently. The pRF was initially modeled as a 2D Gaussian in visual space with four free parameters: $x$ and $y$ describe the pRF center position relative to the fixation point; $\sigma\left(\sigma_{1}\right)$ denotes the SD of the Gaussian, reflecting the spatial spread of the pRF (i.e., pRF size); and $\beta\left(\beta_{1}\right)$ is the response amplitude at $x, y$. In a subsequent analysis, we used a DoG model (based on Zuiderbaan et al., 2012) that incorporated an inhibitory surround in addition to the excitatory center. Because the DoG model is described by a combination of two Gaussians (a central positive isotropic Gaussian and a second larger negative isotropic Gaussian), there are two additional parameters in the model fit: the SD of the larger negative surround $\left(\sigma_{2}\right)$ (i.e., pRF surround size) and the amplitude ratio of the two Gaussians $\left(\beta_{2} / \beta_{1}\right)$.

A linear overlap between the $\mathrm{pRF}$ model and a binary mask of the stimulus across time was used to predict the response of the neuronal population at each vertex. This predicted neuronal response was then convolved with each individual's specific HRF before optimization of the fit between this predicted neuronal response and the measured BOLD responses.

We ran a first pass coarse fit on heavily smoothed functional data [Gaussian kernel with full-width at half-maximum $(\mathrm{FWHM})=8.3$ $\mathrm{mm}]$. Using a 3D search space comprising $15 \times 15 \times 34$ combinations of location $(x, y)$ and pRF size $(\sigma)$, we calculated the Pearson correlation between the time series at each vertex and the search grid to find the parameters with the highest correlation between observed and predicted time series (because it is based on correlation the coarse fit did not include the $\beta$ parameter). All vertices in the defined occipital area were included in this initial model fit. However, vertices for which the goodness-of-fit $\left(R^{2}\right)$ failed to reach 0.05 in the initial coarse fit were not analyzed further. The coarse-fit parameters were then used to seed a subsequent optimization process to fit the $\mathrm{pRF}$ parameters to unsmoothed data at each vertex by minimizing the residual sum of squares between the predicted and observed time series. This model-fitting stage included the $\beta$ parameter. We also used the coarse-fitting parameters from the standard Gaussian model to seed the optimization procedure for the DoG model. Finally, we applied a surface based smoothing kernel of $5 \mathrm{~mm}$ FWHM to deal with any gaps in the maps arising at vertices with poor model fits. This is particularly important for the calculation of cortical surface area and the area subtended by each face in the surface mesh in visual space. See Schwarzkopf et al. (2014) for additional details of the model-fitting procedure.

Visual regions were delineated manually in Freesurfer by displaying pseudocolor-coded maps of polar angle and eccentricity calculated from the pRF analysis (Fig. 2). Visual areas V1-V3 were defined using standard criteria (Sereno et al., 1995; DeYoe et al., 1996; Engel et al., 1997) and V4 was defined as a full hemifield representation adjacent to the ventral portion of V3 (Wandell et al., 2007).

To calculate the cortical magnification factor (CMF) (Harvey and Dumoulin, 2011), we divided the square root of visual area (as determined by the distances of each pRF to the pRF positions of its cortical neighbors) by the corresponding square root of the cortical surface area calculated in the same way. To measure the macroscopic surface area of these regions, we summed the area estimates of all vertices with pRF locations that fell between $2^{\circ}$ and $7^{\circ}$ to avoid edge artifacts.

For the pRF size data $(\sigma)$, we subdivided the vertices into $61^{\circ}$ wide eccentricity bins between $1.5^{\circ}$ and $7.5^{\circ}$, thus avoiding the innermost and outermost pRFs, which were only partially mapped. For each individual, we calculated the mean pRF size $(\sigma)$ for each eccentricity bin within each visual area $\mathrm{V} 1-\mathrm{V} 4$. We then calculated the group mean $(\sigma)$ for each bin in all visual areas and fitted a linear regression to the data (Fig. 3). Any data points $>2$ SDs from the mean were considered outliers and were removed from the group analysis. There was no significant effect of eccentricity, visual area, pRF model, or group on the number of outliers.

For the DoG model, the Gaussian with the larger SD (the negative surround) was subtracted from the smaller Gaussian (the positive center). This results in a change to the effective positive pRF size because the width (size) of the DoG excitatory component results from a combination of the center and surround parameters and their amplitude ratio. Therefore, to allow direct comparison of the excitatory components of the two models, we followed the method of Zuiderbaan et al. (2012) and calculated the FWHM, which measures the width of the positive Gaussian at half the maximum response level. For the size of the inhibitory component of the pRF, we used the SD $\left(\sigma_{2}\right)$ of the negative-surround Gaussian from the DoG model.

To compare between groups, we calculated the difference in (squared) area under the curve (linear regression) fitted to the pRF size data (FWHM or $\sigma$ ) plotted against eccentricity (Fig. 3). To confirm that observed differences were robust, we bootstrapped the fit by resampling each group 1000 times (with replacement), refitted the curves, and recalculated the difference in squared area under the curve for each iteration. The proportion of bootstrapped differences that were opposite to the observed difference was calculated. All probability values were then corrected for multiple comparisons using the false discovery rate (FDR) with a threshold of $q=0.05$.

\section{Results}

For 13 patients and 14 controls, we generated polar angle and eccentricity maps to delineate the early visual areas V1-V4 (Fig. 2). Within these regions of interest, we calculated pRF size (FWHM or $\sigma$ ) and $\mathrm{CMF}$ for $61^{\circ}$ wide eccentricity bins between $1.5^{\circ}$ and $7.5^{\circ}$.

The standard Gaussian model fit showed that people with SZ had significantly smaller pRFs than healthy controls (Fig. 3A), as dem- 
onstrated by significantly less area under the curve fitted to the FWHM by eccentricity data in V1 (bootstrap test, $p=0.01$ ) and V4 $(p=0.018)$, but not V2 $(p=0.166)$ or V3 $(p=0.062) . \mathrm{V} 1$ and V4 survived correction for multiple comparisons using an FDR threshold of 0.05 . This result was considerably stronger for the IQ-/age-matched group, where smaller pRFs were evident in all visual areas $(\mathrm{V} 1 p=0.018, \mathrm{~V} 2 p=0.028$, $\mathrm{V} 3 p=0.023, \mathrm{~V} 4 p=0.006)$ and all survived correction for multiple comparisons. In contrast, although there was a trend for CMF to differ between the two groups in V2 $(p=0.013)$, this did not survive correction for multiple comparisons $(p>0.295$ in all other areas) and there were no significant differences for the IQ-/age-matched groups ( $p>0.112$ in all areas). There was also no difference between groups in the macroscopic surface area of any visual region (independent-samples $t$ tests, all $p>0.358$ for the full group, and all $p>0.286$ for the IQ-/ age-matched group). Nor were there any differences when the surface area of each region was normalized by expressing it as a percentage of overall cortical area (all $p>$ 0.722 for the full group and all $p>0.484$ for the IQ-/age-matched group). There was, however, a difference in total cortical surface area between the two groups, with the SZ group having a significant smaller overall cortical surface area compared with controls ( $p=0.028)$, but this difference did not reach significance for the IQ-/age-matched group $(p=0.063)$. Previous structural imaging studies have found some support for reduced cortical surface area in SZ (Voets et al., 2008; Rimol et al., 2012).

We next estimated the center-surround organization of our pRFs by rerunning the pRF model using a DoG profile, which comprised an excitatory center and a larger inhibitory surround (Zuiderbaan et al., 2012). This analysis revealed that the size $\left(\sigma_{2}\right)$ of the negative-surround Gaussian was significantly smaller in patients with SZ in areas $\mathrm{V} 1(p=0.039), \mathrm{V} 2(p=0.002)$, and V4 $(p=0.002)$, but not in V3 $(p=0.244)$. This difference survived correction for multiple comparisons using an FDR threshold of 0.05 in V2 and V4. For the IQ-/age-matched group, the size of the negative-surround Gaussian was significantly smaller in patients with $\mathrm{SZ}$ in all visual areas (V1 $p=$ $0.012, \mathrm{~V} 2 p<0.001, \mathrm{~V} 3 p=0.043, \mathrm{~V} 4 p=$ 0.005 , and all survived correction for multiple comparisons). This effect is best seen when the pRFs are plotted in 2D (Fig. 4), making it clear that the inhibitory surround was reduced in both size and depth.

The size of the central excitatory zone, measured using the FWHM (for consistency with the standard Gaussian model), was also smaller in V1 $(p=0.013), \mathrm{V} 2(p=0.002)$, and V4 $(p=$

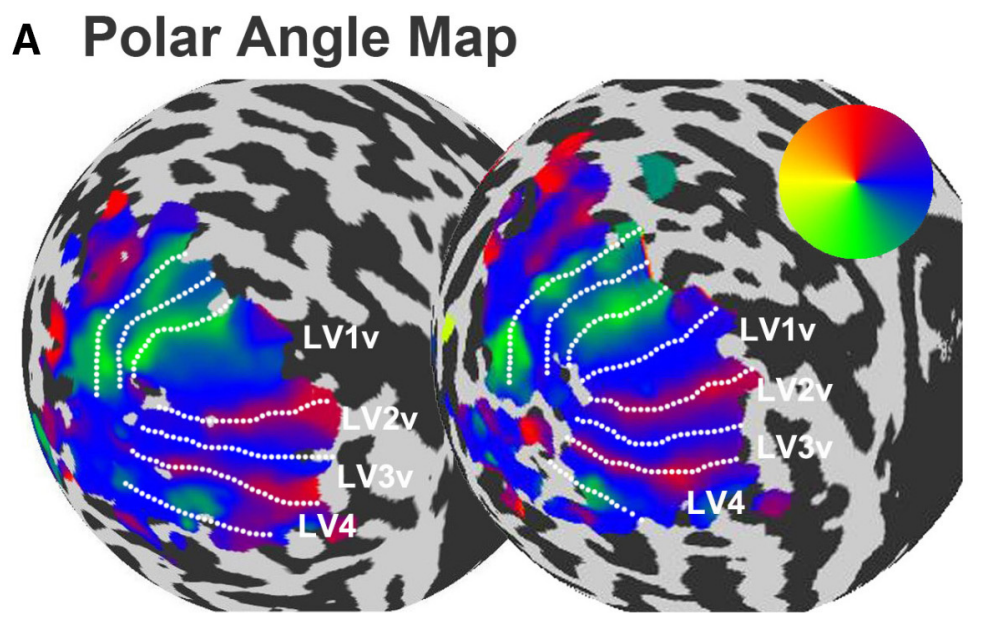

B Eccentricity Map

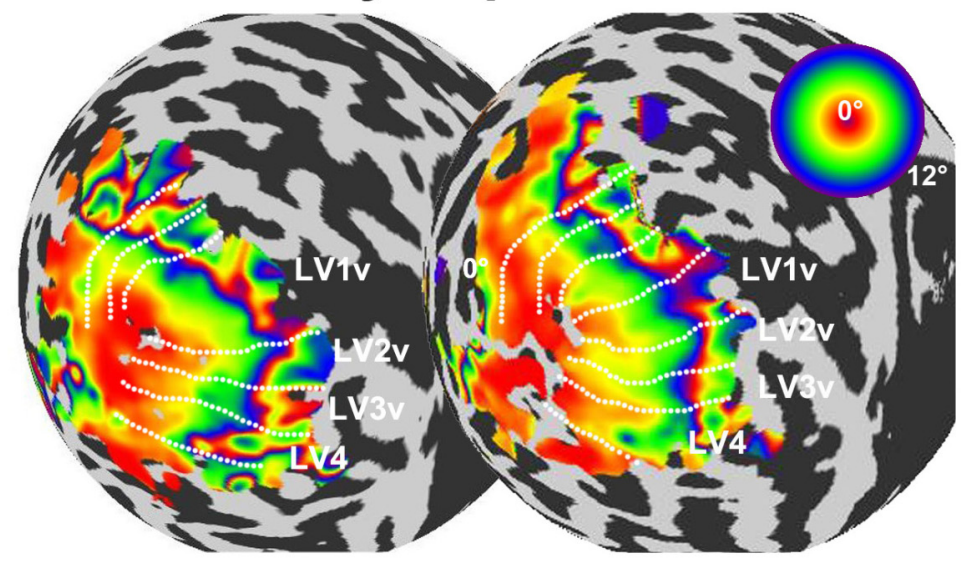

c Prf Size Map

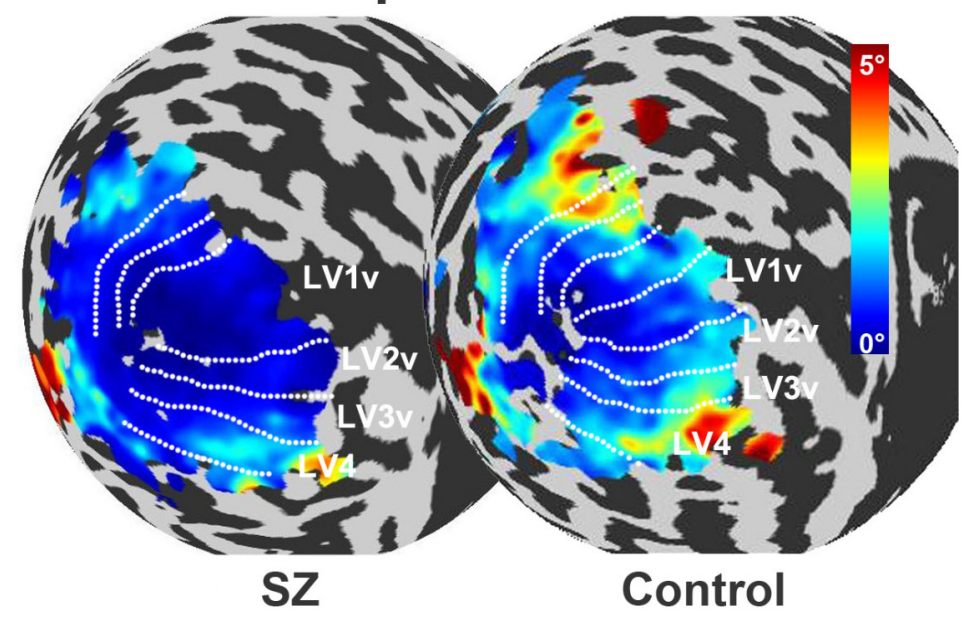

Figure 2. Maps for polar angle $(\boldsymbol{A})$, eccentricity $(\boldsymbol{B})$, and pRF size $(\sigma)(\boldsymbol{C})$, superimposed onto an inflated spherical surface of the left hemisphere for representative individuals from each group. The borders between visual areas are defined in native space using the polar angle and eccentricity map for guidance, indicated by a dotted white contour. These boundaries have been replicated for the eccentricity and pRF size maps. Note that the eccentricity map is cyclical and wraps around at $12^{\circ}$ eccentricity.

0.041 ), but not in V3 ( $p=0.194$ ) (Fig. 3B). However, only V1 and $\mathrm{V} 2$ survived correction for multiple comparisons. The results for the IQ-/age-matched group were similar with a significantly smaller central excitatory zone (FWHM) in V1 $(p=0.009)$, V2 $(p<0.001)$, and V4 $(p=0.047)$, but not V3 $(p=0.191)$. The results for V1 and V2 again survived correction for multiple comparisons. This apparent discrepancy with the excitatory compo- 
A
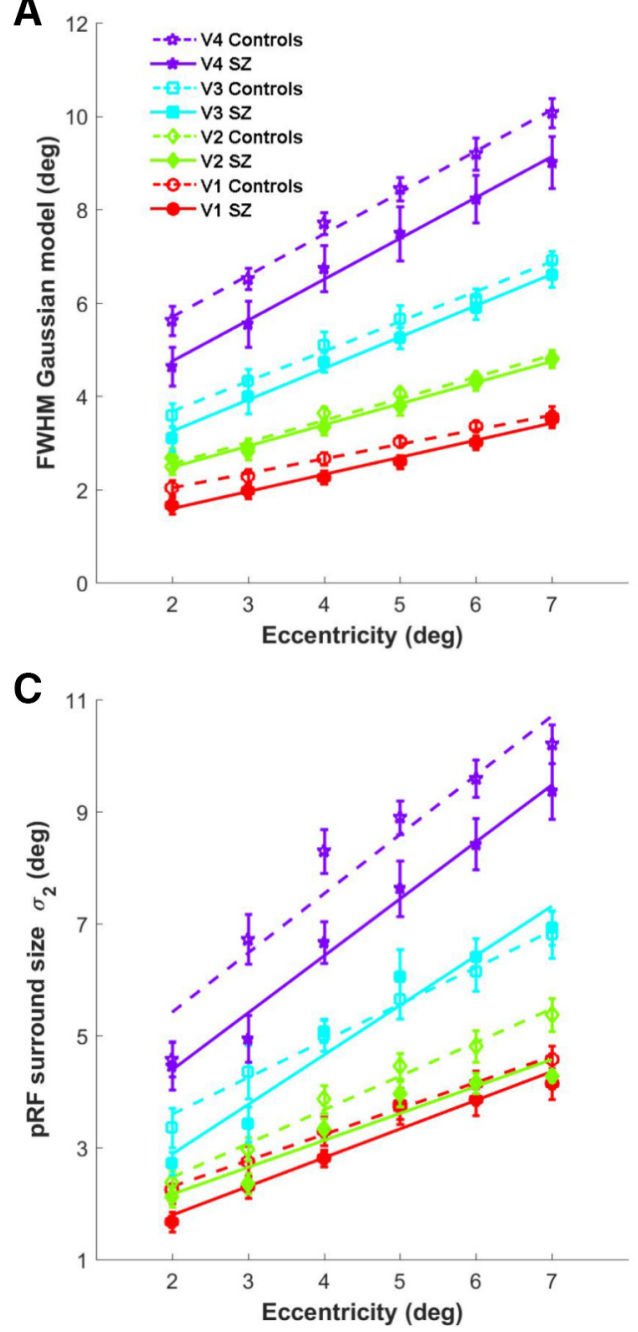

B

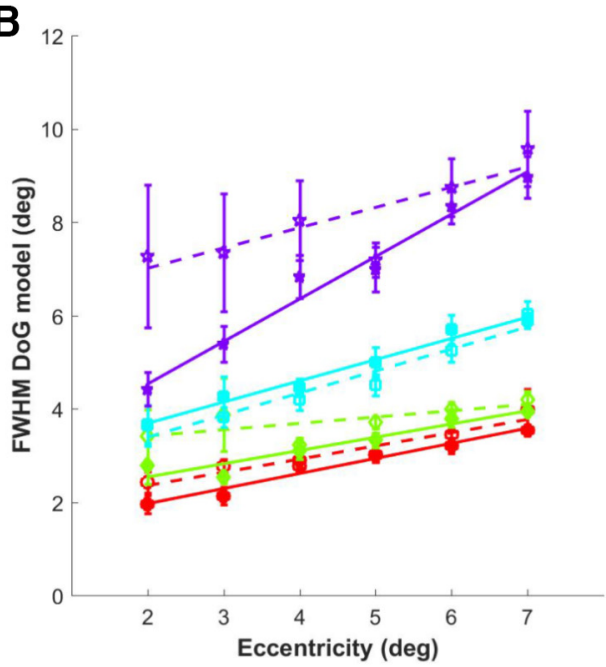

D

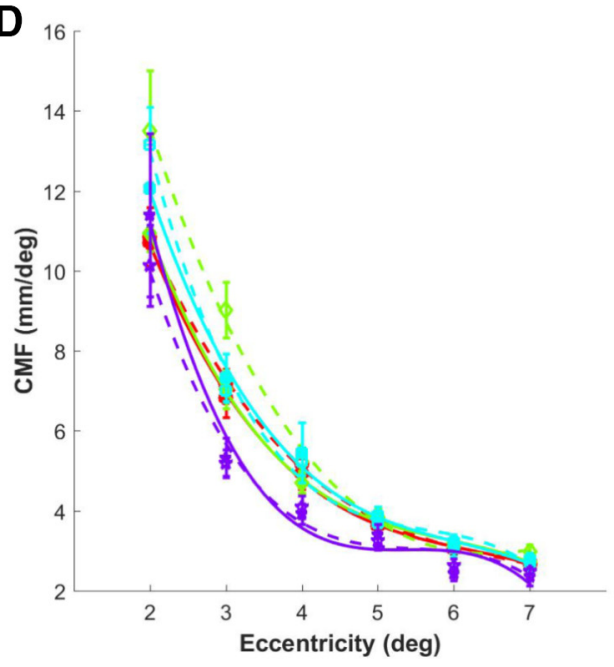

Figure 3. pRF size (width) and CMF averaged across participants within each group (SZ or control) and plotted against eccentricity for visual areas V1 to V4. The data presented here are for the full, unmatched, group ( $n=13$ patients, $n=14$ controls). $A$, FWHM reflects the width of the positive Gaussian at half the maximum response level. We used this as our measure of pRF size. The FWHM increases with eccentricity for both groups in all visual areas (as expected), but is significantly smaller in the SZ group compared with the control group in V1 and V4. For the IQ-/age-matched group, the Gaussian FWHM was significantly smaller in all visual areas (V1-V4) (data not shown in this figure). B, FWHM for the central positive component of the DoG model increases with eccentricity for both groups in all visual areas, but is significantly smaller in the SZ group compared with the control group in V1 and V2. For the IQ-/age-matched group, the DoG FWHM was also significantly smaller in V1 and V2.C, Sigma $\left(\sigma_{2}\right)$ represents pRF size (width) for the negative-surround component of the DoG model. PRF surround size also increases with eccentricity for both groups in all visual areas and is significantly smaller in the SZ group compared with the control group in V2 and V4. For the IQ-/age-matched group, the DoG surround was significantly smaller in V1, V2, and V4. D, CMF decreases with eccentricity in both groups and all visual areas, but there is no significant difference between groups for any visual area. Linear regression was used to fit the pRF size by eccentricity data in $\boldsymbol{A}-\boldsymbol{C}$. A third-degree polynomial was used to fit the CMF data. Symbols denote the group mean; solid lines represent the curve fit for the patient group; dashed lines for the control group. Error bars indicate \pm 1 SEM.

nent of the standard Gaussian model most likely arises due to a change in the central positive profile that results from subtracting the negative surround (the width of the DoG excitatory component is determined by an interaction between $\sigma_{1}$ and $\sigma_{2}$ and their amplitude ratio $\beta_{2} / \beta_{1}$; see Materials and Methods). Alternatively, this finding could be explained by the DoG model failing to capture center-surround pRF configurations accurately in later visual areas (V3 and beyond), an issue raised by Zuiderbaan et al. (2012). The latter might arise due to specific properties of the pRF mapping stimulus or to position scatter in later visual areas causing the center-surround configuration to be lost at the resolution of fMRI. There was certainly much greater variance in our V4 data than any other visual area (Fig. 3).

To determine whether our group difference in pRF size estimates were being driven by other parameters entered into the model fit, we looked for group differences in the amplitude of response to the $\mathrm{pRF}$ mapping stimulus (i.e., the $\beta$ parameter). There was no consistent effect of eccentricity on $\beta$, so we collapsed the data across eccentricity to provide a group mean for each visual area. We observed consistently lower $\beta$ values in SZ for both model fits and lower $\beta$ values for the DoG model compared with the standard Gaussian model. ANOVA (with visual area (4 levels: V1 to V4) and pRF model condition (3 levels: standard Gaussian, DoG center, DoG surround) as withinsubject factors) confirmed a significant main effect of group $(p=$ $0.041)$, pRF condition $(p<0.001)$, and visual area $(p=0.009)$. For all models, the greatest difference occurred in V1, but independent $t$ tests did not reveal a significant difference between groups in V1 for any model (all $p>0.108$; Fig. $5 A-C$ ). The results were similar for the IQ-/age-matched group: a significant main effect of group $(p=0.029)$ and $\mathrm{pRF}$ condition $(p<0.001)$, but not of visual area $(p=0.094)$. 


\section{A Mean pRF (Control)}
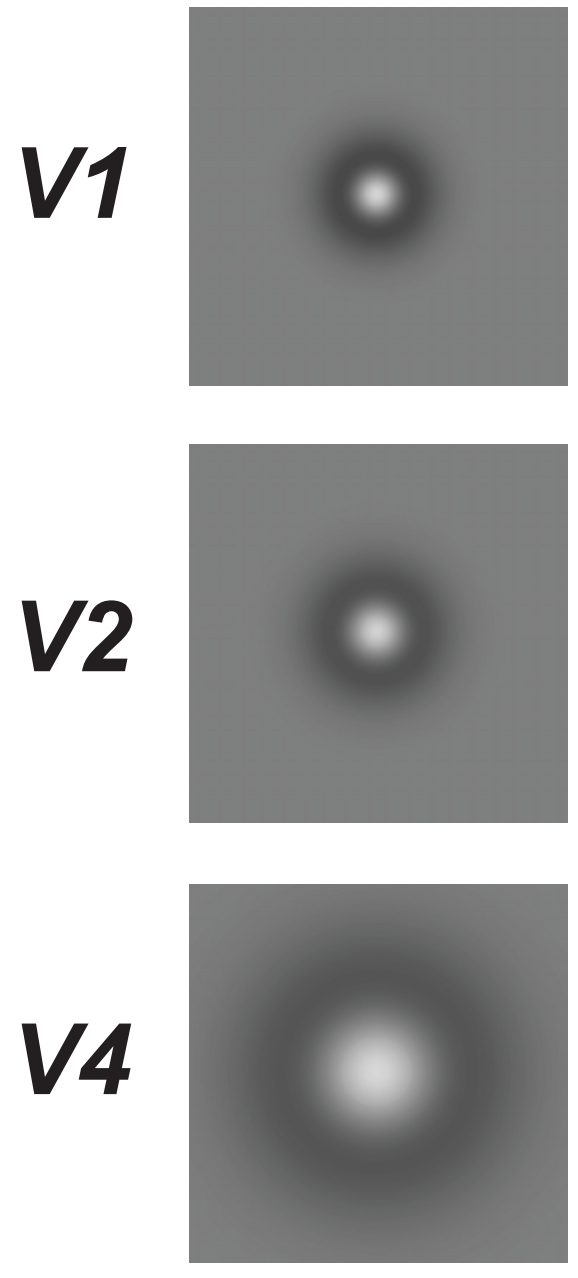
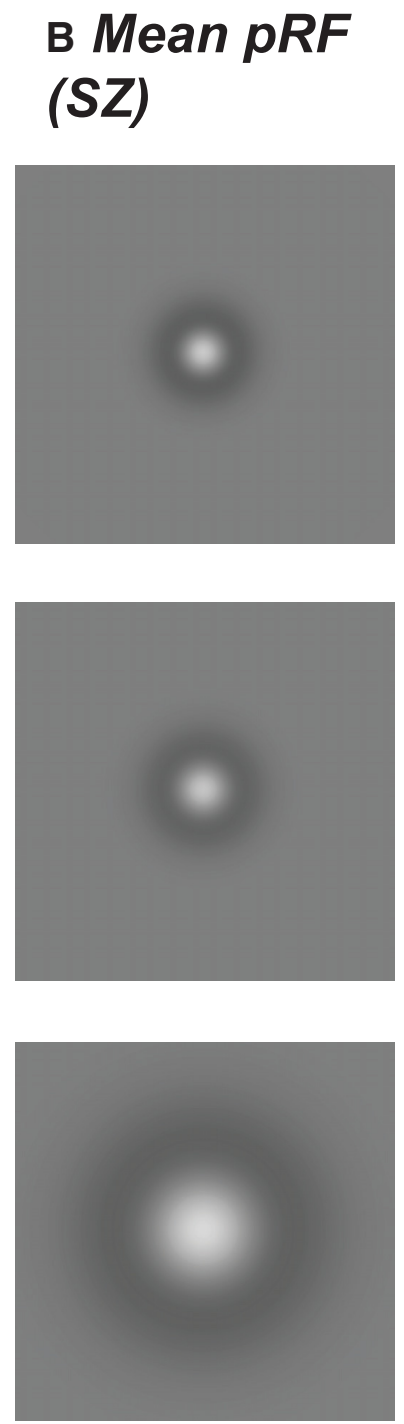

\section{C pRF DoG profile}
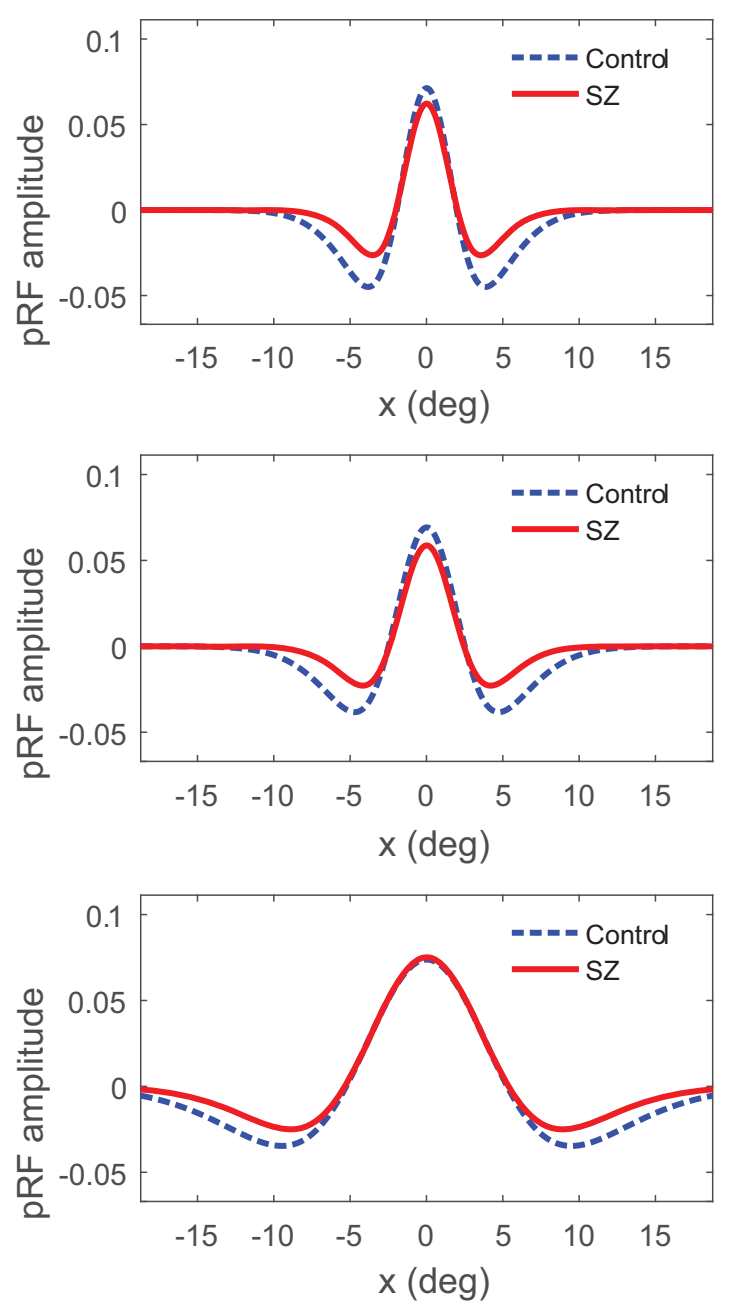

Figure 4. Schematic representation of the mean pRF for the DoG model in V1, V2 and V4. $A, B, 2 D$ plots representing the spatial extent of the mean pRF for the DoG model for controls $(\boldsymbol{A})$ and patients with SZ (B). Bright regions signify excitation and darker regions inhibition. In all areas, patients with SZ exhibited significantly smaller inhibitory surrounds than controls. $C$, 1 D comparison of pRF profiles highlights that not only were the pRFs narrower in V1, V2, and V4, they were also shallower for people with SZ compared with controls.

To investigate whether this group difference in $\beta$ affected the quality of model fit, we then compared the goodness-of-fit $\left(R^{2}\right)$ of the pRF model (Fig. 5D,E) across individuals in the two groups and found that $R^{2}$ was consistently higher for the healthy controls for both models. ANOVA with visual area (four levels: V1-V4) and pRF model condition (two levels: standard Gaussian and DoG) as within-subject factors confirmed a significant main effect of group $(p<0.001)$ and visual area $(p=0.001)$, but no effect of $p R F$ model $(p=0.930)$. The results were similar for the IQ-/age-matched group: significant main effect of group $(p<0.001)$ and visual area $(p=0.002)$, but no effect of $\mathrm{pRF}$ model $(p=0.725)$. In a previous study (Schwarzkopf et al., 2014), we also observed better model fits $\left(R^{2}\right)$ with higher response amplitudes $(\beta)$. However, poor model fits, which can occur due to increased noise in the data (eye movements, head movement, brain pulsatility, and optical defocus), have been shown to increase pRF size estimates for both center and surround components; therefore, it is unlikely that this is the factor driving our main effect of reduced pRF size in the patient group (Dumoulin and Wandell, 2008; Zuiderbaan et al., 2012). It should be noted, however, that $R^{2}$ for both models is consistently better in V1 than V4 [paired $t$-tests comparing $R^{2}$ in V1 and V4 for full group: Gaussian model $(p=0.001)$, DoG model $(p=0.001)$ and matched group: Gaussian model $(p=0.003)$, DoG model $(p=0.024)$ ], which might suggest that our findings for early visual areas are more robust than those for later areas, a finding that has been noted before for the DoG model (Zuiderbaan et al., 2012).

We also investigated whether group differences in the shape and amplitude of the individually fitted HRFs could have affected our results, but we found no significant difference in the shape (area under the curve for the full group, $p=0.209$; for the IQ-/ age-matched group, $p=0.388$ ) or amplitude (independentsamples $t$ test for full group, $p=0.683$; for the IQ-/age-matched group, $p=0.781$ ) of the fitted HRF, consistent with a previous report that showed the hemodynamic response to be intact in medicated patients with SZ (Barch et al., 2003).

To further investigate the reliability of our data, we checked the ability of all individuals to maintain central fixation during the mapping scan runs. Eye movements were recorded through- 


\section{A Standard Gaussian}

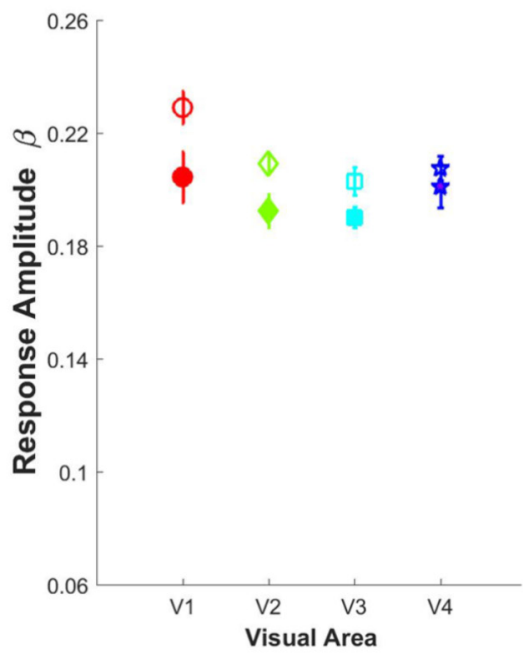

D Standard Gaussian

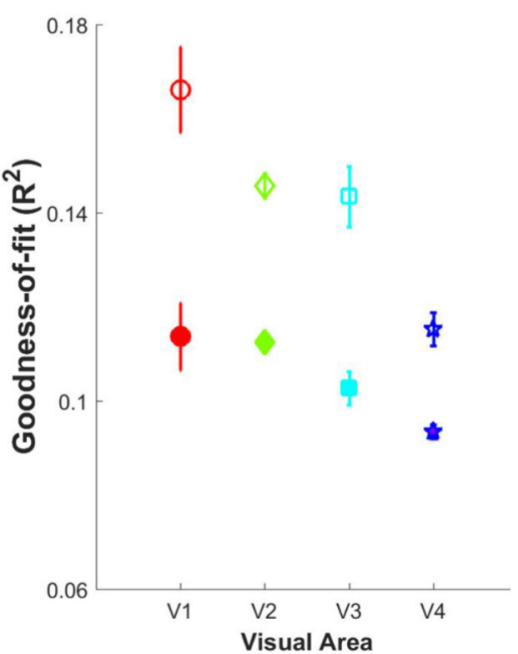

B DoG centre

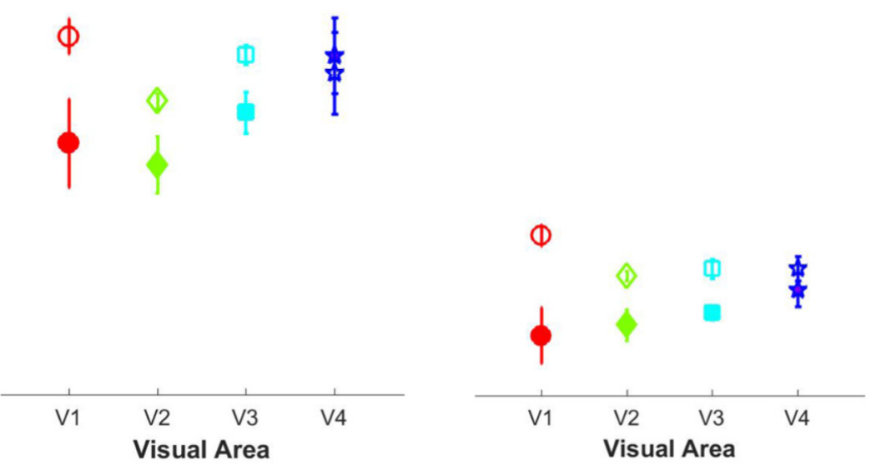

E

\section{DoG}
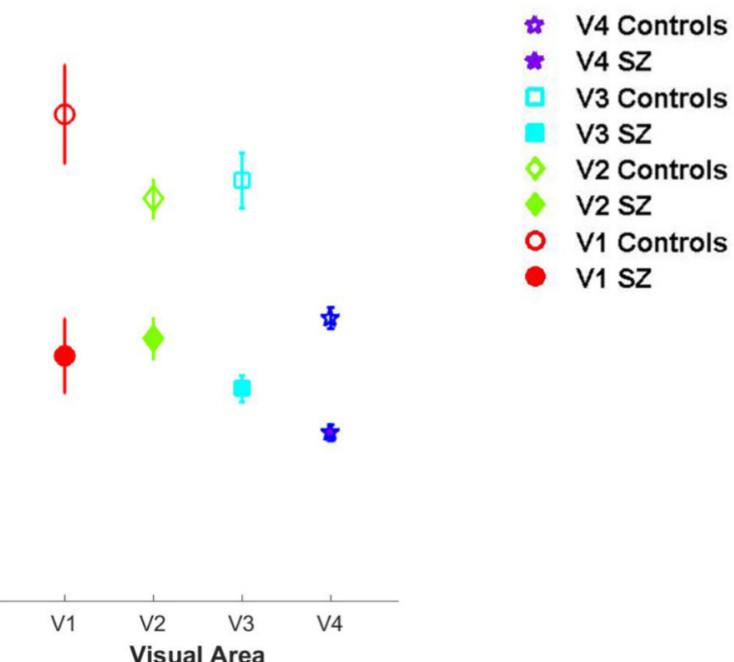

\section{DoG Surround}

Figure 5. Estimates of response amplitude $(\beta)$ for $(\boldsymbol{A})$ the standard Gaussian model, $(\boldsymbol{B})$ the central component of the DoG model, and $(\boldsymbol{C})$ the surround component of the DoG model. Data have been collapsed across eccentricity with the group mean plotted for each visual area. Beta estimates were consistently lower in the SZ group for both model fits. The goodness-of-fit is plotted in (D), for the standard model and $(\boldsymbol{E})$, for the DoG model. Model fits were consistently better for the control group, and better in V1 compared with V4 for both groups. Error bars indicate \pm 1 SEM.

out all scan runs and we found no significant difference in the average SD of eye position between groups for either the horizontal or vertical axes ( $\left.x_{\text {eye }}: p=0.178 ; y_{\text {eye }}: p=0.522\right)$. We also extracted the head movement parameters calculated during the realignment stage and confirmed that there was no significant difference in the mean SD for head translation $\left(x_{\text {head }}: p=0.228 ; y_{\text {head }}: p=0.088 ; z_{\text {head }}: p=\right.$ 0.098 ) or rotation (pitch: $p=0.056$; roll: $p=0.129$, yaw $p=0.094$ ). There was also no significant difference in the mean SD for head translation $\left(x_{\text {head }}: p=0.175 ; y_{\text {head }}: p=0.070 ; z_{\text {head }}: p=0.156\right)$ or rotation (pitch: $p=0.052$; roll: $p=0.136$, yaw $p=0.076$ ) for the IQ-/age-matched group. Finally, analysis of the behavioral performance in the central fixation task also revealed no significant difference between groups (based on hit rates for the full group: $p=0.123$ and age/IQ group $p=0.622$ ).

To assess whether pRF size was associated with the severity of symptoms within the patient group, we correlated fMRI parameters with scores on the PANSS, including total PANSS score, total positive, total negative, and total general psychopathology subscale scores. We found no significant correlations between any of the PANSS scores and pRF size nor between pRF size and medication dose (the $\alpha$ level was set to 0.0083 , reflecting Bonferroni correction for six comparisons; 6 PANSS measures assessed; Table 1). Although PANSS is considered the gold standard for measuring severity of symptoms (positive and negative), we might have found a correlation with our data if we had used one of the newer scales such as the Brief Negative Symptom Scale (BNSS; Kirkpatrick et al., 2011), which captures cognitive and negative symptoms better. We recommend using both of these scales in future studies on perception.

\section{Discussion}

Our results indicate that the fine-grained functional architecture of early visual cortex is different in patients with SZ compared with healthy controls. A DoG model revealed that, not only was the central excitatory component of the $\mathrm{pRF}$ reduced in size in SZ (most reliably in V1 and V2), but the inhibitory surround 
was also narrower and shallower in V1, V2, and V4. Similar to a previous fMRI study (Wynn et al., 2008), we found no difference in the macroscopic organization/surface area of early visual areas between groups. Although the exact relationship between pRFs estimated using fMRI and the RFs of single neurons measured electrophysiologically remains unresolved (Logothetis et al., 2001), we do know that there is good agreement between pRF properties in humans measured using fMRI and subdural electrodes (Yoshor et al., 2007; Winawer et al., 2011) and the properties of RFs in nonhuman primates measured electrophysiologically (see Fig. 9 in Dumoulin and Wandell, 2008). Therefore, the reduction in pRF size observed here is likely to reflect a reduction in the RF size of individual neurons.

Our results are consistent with growing evidence that the fundamental pathology in SZ is a dysfunction in synaptic transmission and neuronal connectivity (Frankle et al., 2003) in association with a change in the underlying neural architecture. In support of this hypothesis, postmortem examination suggests that mean neuronal somal size is reduced in the prefrontal cortex of patients with SZ (Rajkowska et al., 1998) and this is thought to reflect a disturbance in neuronal connectivity and axonal architecture. A reduction in spine density on pyramidal cells and evidence that the cortical terminal fields are smaller than normal in the brains of patients with SZ (Lewis and Glantz, 1995) adds further weight to the hypothesis that synaptic contacts are relatively impoverished in this group (Selemon and Goldman-Rakic, 1999). Therefore, reduced $\mathrm{pRF}$ size in SZ may provide clues to abnormal synaptic transmission and neuronal connectivity, a feature that is difficult to assess postmortem.

It is this impaired lateral connectivity that is thought to lead to an imbalance between cortical excitation and inhibition resulting in reduced surround suppression in patients with SZ (Must et al., 2004). Surround suppression belongs to a class of neural computation known as gain control that serves to maximize the operating range of neurons, a ubiquitous feature of processing throughout the sensory cortex (Carandini and Heeger, 2011). Indeed, abnormal gain control has been proposed as the mechanism responsible for a range of visual deficits in SZ, including reduced susceptibility to contextual illusions such as the contrast-contrast phenomenon and orientation-specific surround suppression (Chubb et al., 1989; Dakin et al., 2005; Yoon et al., 2009), as well as impaired motion perception (Kim et al., 2006) and contour integration (Robol et al., 2013). Neurons in the M-pathway seem to play a central role in contrast gain control in V1. For example, M-cells in the macaque retina are prone to surround suppression (Solomon et al., 2006) and the neurons prone to the strongest surround suppression in primate visual cortex (in layers $4 \mathrm{C} \alpha$ and $4 \mathrm{~B}$ ) predominantly receive their input from M-cells (Sceniak et al., 2001). Properties of $\mathrm{M}$-cells (fast response times and low spatial resolution) make them a suitable neural substrate for cortical gain control (Lennie, 1980), a process considered to reflect both intrinsic neural properties and short-range lateral interactions between neurons (Heeger, 1992). fMRI studies have also indicated a dysfunction in the magnocellular pathway in SZ (Martínez et al., 2008) and our finding of a bias toward smaller pRF size in SZ is suggestive of a loss of neurons with large receptive fields, which is consistent with a selective loss of Mcells. However, it should be noted that we did not design our stimuli to bias responses toward one cell type or other. Instead, by using a large range of SFs and relatively high contrast levels, our pRF mapping stimulus was designed to activate both magnocellular and parvocellular pathways.

NMDA receptors are also known to play a prominent role in cortical gain control within the magnocellular visual system
(Kwon et al., 1992) and impaired NMDA receptor-mediated neurotransmission is thought to give rise to altered GABA receptor function, a widespread observation in SZ (Lewis, 2000). Postmortem studies show a pancortical reduction in neuronal GABA concentration in patients with SZ (Hashimoto et al., 2008), which is thought to result in abnormal gating of sensory information due to anomalous inhibitory modulation of cortical circuits (Benes and Berretta, 2001). These findings broadly support the hypothesis that reduced GABA in SZ leads to impairments in cognitive and visual tasks that involve inhibitory mechanisms as a consequence of abnormal gain control. Certainly, reduced concentration of GABA in primary visual cortex has been linked to reduced levels of gain control in SZ (Yoon et al., 2010).

Visual processing relies heavily on integration to bind together local information (e.g., brightness, color, orientation, motion) into coherent/unambiguous percepts of global structure. SZ has been linked with a deficit in such integration (Silverstein and Keane, 2011), leading to patients performing "better" than control subjects under conditions when global integration would normally interfere with responses to individual elements (Place and Gilmore, 1980; Rief, 1991; Robol et al., 2013). For example, we have shown that patient orientation discrimination thresholds for isolated Gabor targets are less elevated by the presence of disruptive clutter ("crowding") than controls, but this effect is largely driven by patients' poor orientation discrimination of the isolated target (Robol et al., 2013). Contour integration paradigms (Field et al., 1993) have been used widely to probe the grouping deficit in SZ and indicate that patients require closer spacing of elements to detect contours (Silverstein et al., 2000; Uhlhaas et al., 2006a). These results, and related findings that patients with SZ exhibit abnormal flanker facilitation (Must et al., 2004; Kéri et al., 2005), have been taken to indicate weaker interactions between orientation detectors, most likely mediated by abnormal horizontal connectivity in V1. Certainly, broader orientation tuning has been observed in SZ (Rokem et al., 2011) and has previously been associated with reduced GABAergic inhibition (Edden et al., 2009). Reduced GABA levels have also been associated with reduced orientation-tuned surround suppression in SZ (Yoon et al., 2010). The latter could result from a reduction in either the depth of tuned suppression or an overall reduction in tuning. Therefore, it is possible that the reduction in size and depth of inhibition in the pRF surrounds that we observed in our data leads to broader orientation tuning.

In the present study, we concentrated our investigation on cortical visual areas because previous psychophysical findings have associated deficits in visual surround suppression with a predominantly cortical locus (Yoon et al., 2010; Tibber et al., 2013). However, it is possible that the change in $\mathrm{pRF}$ characteristics observed here are inherited from an earlier, subcortical, or even retinal origin. Certainly, changes to retinal structure and function have been documented in SZ, including loss of retinal ganglion cell axons, reduced GABA-related lateral inhibition, and dopaminergic abnormalities (for review, see Silverstein and Rosen, 2015), which may have a feedforward impact on LGN and cortical function. Imaging subcortical visual nuclei with fMRI is technically challenging (Wall et al., 2009); however, pRF mapping has provided greater precision and more detailed maps than traditional methods. Using a standard Gaussian pRF model, the spatial tuning properties of subcortical nuclei have been mapped recently in healthy individuals (DeSimone et al., 2015). The next step would be to use a DoG model to probe centersurround properties of pRFs in these areas and, if achievable, translate these methods to clinical populations such as SZ. The findings may shed light on the level at which these functional changes can be 
detected within the visual hierarchy. However, it should be noted that human postmortem studies have failed to find evidence for structural differences in the LGN of patients with SZ (DorphPetersen et al., 2009).

Among all of the basic symptoms assessed using the Bonn scale (used to identify individuals at risk of psychosis), visual distortions have the highest sensitivity for conversion to a psychotic disorder (Klosterkötter et al., 2001) and visual impairments in children are more strongly associated with later development of SZ than any other form of sensory impairment (Schubert et al., 2005). Altered neuronal density (Selemon et al., 1995), neuron number (DorphPetersen et al., 2007), and somal size (Rajkowska et al., 1998) all point toward some form of altered neural development. In prefrontal cortex, a reduction in mean neuronal size in the context of dramatically increased density (Rajkowska et al., 1998) suggests a subtle cellular change rather than neuronal loss, which was interpreted by the investigators as a developmental rather than a neurodegenerative change. Our findings are consistent with this hypothesis and point toward a specific change in neuronal architecture within early visual cortex that is not related to medication type or dose. Our data cannot determine at what stage in development this change occurs, but the relatively short time required to collect sufficient fMRI data to perform $\mathrm{pRF}$ analysis makes this a suitable technique for longitudinal tracking of changes in visual cortical architecture that could accompany the progression of SZ.

In summary, we propose that an imbalance between excitatory and inhibitory signals in SZ drives a change in the centersurround configuration of pRFs measured using fMRI. In turn, this imbalance results in broader orientation tuning and abnormal horizontal connectivity, which can ultimately explain a range of visual deficits experienced by people with SZ. Indeed, computational modeling of center-surround interactions - varying the number and strength of connections, the number of inhibitory neurons, and the time constant of GABAergic synapses-suggests that a combination of factors can result in the perceptual deficits observed (Metzner et al., 2014).

\section{References}

Barch DM, Mathews JR, Buckner RL, Maccotta L, Csernansky JG, Snyder AZ (2003) Hemodynamic responses in visual, motor, and somatosensory cortices in schizophrenia. Neuroimage 20:1884-1893. CrossRef Medline

Barch DM, Carter CS, Dakin SC, Gold J, Luck SJ, Macdonald A 3rd, Ragland JD, Silverstein S, Strauss ME (2012) The clinical translation of a measure of gain control: the contrast-contrast effect task. Schizophr Bull 38: 135-143. CrossRef Medline

Benes FM, Berretta S (2001) GABAergic interneurons: implications for understanding schizophrenia and bipolar disorder. Neuropsychopharmacology 25:1-27. CrossRef Medline

Brainard DH (1997) The Psychophysics Toolbox. Spat Vis 10:433-436. CrossRef Medline

Butler PD, Schechter I, Zemon V, Schwartz SG, Greenstein VC, Gordon J, Schroeder CE, Javitt DC (2001) Dysfunction of early-stage visual processing in schizophrenia. Am J Psychiatry 158:1126-1133. CrossRef Medline

Butler PD, Zemon V, Schechter I, Saperstein AM, Hoptman MJ, Lim KO, Revheim N, Silipo G, Javitt DC (2005) Early-stage visual processing and cortical amplification deficits in schizophrenia. Arch Gen Psychiatry 62: 495-504. CrossRef Medline

Butler PD, Silverstein SM, Dakin SC (2008) Visual perception and its impairment in schizophrenia. Biol Psychiatry 64:40-47. CrossRef Medline

Carandini M, Heeger DJ (2011) Normalization as a canonical neural computation. Nat Rev Neurosci 13:51-62. CrossRef Medline

Cavanaugh JR, Bair W, Movshon JA (2002) Nature and interaction of signals from the receptive field center and surround in macaque V1 neurons. J Neurophysiol 88:2530-2546. CrossRef Medline

Chen Y, Levy DL, Sheremata S, Holzman PS (2004) Compromised latestage motion processing in schizophrenia. Biol Psychiatry 55:834-841. CrossRef Medline
Chubb C, Sperling G, Solomon JA (1989) Texture interactions determine perceived contrast. Proc Natl Acad Sci U S A 86:9631-9635. CrossRef Medline

Dakin S, Carlin P, Hemsley D (2005) Weak suppression of visual context in chronic schizophrenia. Curr Biol 15:R822-R824. CrossRef Medline

DeSimone K, Viviano JD, Schneider KA (2015) Population receptive field estimation reveals new retinotopic maps in human subcortex. J Neurosci 35:9836-9847. CrossRef Medline

DeYoe EA, Carman GJ, Bandettini P, Glickman S, Wieser J, Cox R, Miller D, Neitz J (1996) Mapping striate and extrastriate visual areas in human cerebral cortex. Proc Natl Acad Sci U S A 93:2382-2386. CrossRef Medline

Dorph-Petersen KA, Pierri JN, Wu Q, Sampson AR, Lewis DA (2007) Primary visual cortex volume and total neuron number are reduced in schizophrenia. J Comp Neurol 501:290-301. CrossRef Medline

Dorph-Petersen KA, Caric D, Saghafi R, Zhang W, Sampson AR, Lewis DA (2009) Volume and neuron number of the lateral geniculate nucleus in schizophrenia and mood disorders. Acta Neuropathologica 117:369-384. CrossRef Medline

Dumoulin SO, Wandell BA (2008) Population receptive field estimates in human visual cortex. Neuroimage 39:647-660. CrossRef Medline

Edden RA, Muthukumaraswamy SD, Freeman TC, Singh KD (2009) Orientation discrimination performance is predicted by GABA concentration and gamma oscillation frequency in human primary visual cortex. J Neurosci 29:15721-15726. CrossRef Medline

Engel SA, Glover GH, Wandell BA (1997) Retinotopic organization in human visual cortex and the spatial precision of functional MRI. Cereb Cortex 7:181-192. CrossRef Medline

Field DJ, Hayes A, Hess RF (1993) Contour integration by the human visual system: evidence for a local "association field." Vision Res 33:173-193. CrossRef Medline

Frankle WG, Lerma J, Laruelle M (2003) The synaptic hypothesis of schizophrenia. Neuron 39:205-216. CrossRef Medline

Harvey BM, Dumoulin SO (2011) The relationship between cortical magnification factor and population receptive field size in human visual cortex: constancies in cortical architecture. J Neurosci 31:13604-13612. CrossRef Medline

Hashimoto T, Bazmi HH, Mirnics K, Wu Q, Sampson AR, Lewis DA (2008) Conserved regional patterns of GABA-related transcript expression in the neocortex of subjects with schizophrenia. Am J Psychiatry 165:479-489. CrossRef Medline

Heeger DJ (1992) Normalization of cell responses in cat striate cortex. Vis Neurosci 9:181-197. CrossRef Medline

Kay SR, Fiszbein A, Opler LA (1987) The positive and negative syndrome scale (PANSS) for schizophrenia. Schizophr Bull 13:261-276. CrossRef Medline

Kéri S, Kelemen O, Benedek G, Janka Z (2005) Lateral interactions in the visual cortex of patients with schizophrenia and bipolar disorder. Psychol Med 35:1043-1051. CrossRef Medline

Kim D, Wylie G, Pasternak R, Butler PD, Javitt DC (2006) Magnocellular contributions to impaired motion processing in schizophrenia. Schizophr Res 82:1-8. CrossRef Medline

Kirkpatrick B, Strauss GP, Nguyen L, Fischer BA, Daniel DG, Cienfuegos A, Marder SR (2011) The brief negative symptom scale: psychometric properties. Schizophr Bull 37:300-305. CrossRef Medline

Klosterkötter J, Hellmich M, Steinmeyer EM, Schultze-Lutter F (2001) Diagnosing schizophrenia in the initial prodromal phase. Arch Gen Psychiatry 58:158-164. CrossRef Medline

Kwon YH, Nelson SB, Toth LJ, Sur M (1992) Effect of stimulus contrast and size on NMDA receptor activity in cat lateral geniculate nucleus. J Neurophysiol 68:182-196. Medline

Lennie P (1980) Parallel visual pathways: a review. Vision Res 20:561-594. CrossRef Medline

Lewis DA (2000) GABAergic local circuit neurons and prefrontal cortical dysfunction in schizophrenia. Brain Res Brain Res Rev 31:270-276. CrossRef Medline

Lewis DA, Glantz LA (1995) Selective decrease of synaptophysin immunoreactivity in the prefrontal cortex of schizophrenic subjects. Schizophrenia Research 15:64.

Logothetis NK, Pauls J, Augath M, Trinath T, Oeltermann A (2001) Neurophysiological investigation of the basis of the fMRI signal. Nature 412: 150-157. CrossRef Medline

Martínez A, Hillyard SA, Dias EC, Hagler DJ Jr, Butler PD, Guilfoyle DN, Jalbrzikowski M, Silipo G, Javitt DC (2008) Magnocellular pathway im- 
pairment in schizophrenia: evidence from functional magnetic resonance imaging. J Neurosci 28:7492-7500. CrossRef Medline

Melnick MD, Harrison BR, Park S, Bennetto L, Tadin D (2013) A strong interactive link between sensory discriminations and intelligence. Curr Biol 23:1013-1017. CrossRef Medline

Metzner C, Schweikard A, Zurowski B (2014) Computational multifactoriality in a detailed neural network model resembling centresurround suppression deficits in schizophrenia. BMC Neuroscience 15(Suppl 1):1. CrossRef Medline

Murray RM, Lewis SW (1987) Is schizophrenia a neurodevelopmental disorder? Br Med J (Clin Res Ed) 295:681-682. CrossRef

Must A, Janka Z, Benedek G, Kéri S (2004) Reduced facilitation effect of collinear flankers on contrast detection reveals impaired lateral connectivity in the visual cortex of schizophrenia patients. Neurosci Lett 357: 131-134. CrossRef Medline

Nelson HE, Willison JR (1991) The National Adult Reading Test (NART). Windsor, UK: NFER-Nelson.

O'Donnell BF, Swearer JM, Smith LT, Nestor PG, Shenton ME, McCarley RW (1996) Selective deficits in visual perception and recognition in schizophrenia. Am J Psychiatry 153:687-692. CrossRef Medline

Phillips WA, Clark A, Silverstein SM (2015) On the functions, mechanisms, and malfunctions of intracortical contextual modulation. Neurosci Biobehav Rev 52:1-20. CrossRef Medline

Place EJ, Gilmore GC (1980) Perceptual organization in schizophrenia. J Abnorm Psychol 89:409-418. CrossRef Medline

Rajkowska G, Selemon LD, Goldman-Rakic PS (1998) Neuronal and glial somal size in the prefrontal cortex: a postmortem morphometric study of schizophrenia and Huntington disease. Arch Gen Psychiatry 55:215-224. CrossRef Medline

Rief W (1991) Visual perceptual organization in schizophrenic patients. $\mathrm{Br}$ J Clin Psychol 30:359-366. CrossRef Medline

Rimol LM, Nesvåg R, Hagler DJ Jr, Bergmann O, Fennema-Notestine C, Hartberg CB, Haukvik UK, Lange E, Pung CJ, Server A, Melle I, Andreassen OA, Agartz I, Dale AM (2012) Cortical volume, surface area, and thickness in schizophrenia and bipolar disorder. Biol Psychiatry 71: 552-560. CrossRef Medline

Robol V, Tibber MS, Anderson EJ, Bobin T, Carlin P, Shergill SS, Dakin SC (2013) Reduced crowding and poor contour detection in schizophrenia are consistent with weak surround inhibition. PLoS One 8:e60951. CrossRef Medline

Rokem A, Yoon JH, Ooms RE, Maddock RJ, Minzenberg MJ, Silver MA (2011) Broader visual orientation tuning in patients with schizophrenia. Front Hum Neurosci 5:127. CrossRef Medline

Sceniak MP, Hawken MJ, Shapley R (2001) Visual spatial characterization of macaque V1 neurons. J Neurophysiol 85:1873-1887. Medline

Schallmo MP, Sponheim SR, Olman CA (2015) Reduced contextual effects on visual contrast perception in schizophrenia and bipolar affective disorder. Psychol Med 45:3527-3537. CrossRef Medline

Schubert EW, Henriksson KM, McNeil TF (2005) A prospective study of offspring of women with psychosis: visual dysfunction in early childhood predicts schizophrenia-spectrum disorders in adulthood. Acta Psychiatr Scand 112:385-393. CrossRef Medline

Schwarzkopf DS, Anderson EJ, de Haas B, White SJ, Rees G (2014) Larger extrastriate population receptive fields in autism spectrum disorders. J Neurosci 34:2713-2724. CrossRef Medline

Selemon LD, Goldman-Rakic PS (1999) The reduced neuropil hypothesis: a circuit based model of schizophrenia. Biol Psychiatry 45:17-25. CrossRef Medline

Selemon LD, Rajkowska G, Goldman-Rakic PS (1995) Abnormally high neuronal density in the schizophrenic cortex: a morphometric analysis of prefrontal area 9 and occipital area 17. Arch Gen Psychiatry 52:805-818; discussion 819-820. Medline

Sereno MI, Dale AM, Reppas JB, Kwong KK, Belliveau JW, Brady TJ, Rosen BR, Tootell RB (1995) Borders of multiple visual areas in humans revealed by functional magnetic resonance imaging. Science 268:889-893. CrossRef Medline

Silverstein SM, Keane BP (2011) Perceptual organization impairment in schizophrenia and associated brain mechanisms: review of research from 2005 to 2010. Schizophr Bull 37:690-699. CrossRef Medline

Silverstein SM, Rosen R (2015) Schizophrenia and the eye. Schizophrenia research Cognition 2:46-55. CrossRef Medline

Silverstein SM, Kovács I, Corry R, Valone C (2000) Perceptual organization, the disorganization syndrome, and context processing in chronic schizophrenia. Schizophr Res 43:11-20. CrossRef Medline

Silverstein S, Keane BP, Blake R, Giersch A, Green M, Kéri S (2015) Vision in schizophrenia: why it matters. Front Psychol 6:41. Medline

Slaghuis WL (1998) Contrast sensitivity for stationary and drifting spatial frequency gratings in positive- and negative-symptom schizophrenia. J Abnorm Psychol 107:49-62. CrossRef Medline

Solomon SG, Lee BB, Sun H (2006) Suppressive surrounds and contrast gain in magnocellular-pathway retinal ganglion cells of macaque. J Neurosci 26:8715-8726. CrossRef Medline

Tadin D, Kim J, Doop ML, Gibson C, Lappin JS, Blake R, Park S (2006) Weakened center-surround interactions in visual motion processing in schizophrenia. J Neurosci 26:11403-11412. CrossRef Medline

Tibber MS, Anderson EJ, Bobin T, Antonova E, Seabright A, Wright B, Carlin P, Shergill SS, Dakin SC (2013) Visual surround suppression in schizophrenia. Front Psychol 4:88. CrossRef Medline

Tibber MS, Anderson EJ, Bobin T, Carlin P, Shergill SS, Dakin SC (2015) Local and global limits on visual processing in schizophrenia. PLoS One 10:e0117951. CrossRef Medline

Uhlhaas PJ, Phillips WA, Mitchell G, Silverstein SM (2006a) Perceptual grouping in disorganized schizophrenia. Psychiatry Res 145:105-117. CrossRef Medline

Uhlhaas PJ, Linden DE, Singer W, Haenschel C, Lindner M, Maurer K, Rodriguez E (2006b) Dysfunctional long-range coordination of neural activity during Gestalt perception in schizophrenia. J Neurosci 26:8168 8175. CrossRef Medline

Voets NL, Hough MG, Douaud G, Matthews PM, James A, Winmill L, Webster P, Smith S (2008) Evidence for abnormalities of cortical development in adolescent-onset schizophrenia. Neuroimage 43:665-675. CrossRef Medline

Wall MB, Walker R, Smith AT (2009) Functional imaging of the human superior colliculus: an optimised approach. Neuroimage 47:1620-1627. CrossRef Medline

Wandell BA, Winawer J (2015) Computational neuroimaging and population receptive fields. Trends Cogn Sci 19:349-357. CrossRef Medline

Wandell BA, Dumoulin SO, Brewer AA (2007) Visual field maps in human cortex. Neuron 56:366-383. CrossRef Medline

Weinberger DR (1987) Implications of normal brain development for the pathogenesis of schizophrenia. Arch Gen Psychiatry 44:660-669. CrossRef Medline

Winawer J, Rauschecker AM, Wandell B (2011) Population receptive fields in human visual cortex measured with subdural electrodes. J Vis 11:1196.

Wynn JK, Green MF, Engel S, Korb A, Lee J, Glahn D, Nuechterlein KH, Cohen MS (2008) Increased extent of object-selective cortex in schizophrenia. Psychiatry Res 164:97-105. CrossRef Medline

Yang E, Tadin D, Glasser DM, Hong SW, Blake R, Park S (2013) Visual context processing in schizophrenia. Clin Psychol Sci 1:5-15. CrossRef Medline

Yoon JH, Rokem AS, Silver MA, Minzenberg MJ, Ursu S, Ragland JD, Carter CS (2009) Diminished orientation-specific surround suppression of visual processing in schizophrenia. Schizophr Bull 35:1078-1084. CrossRef Medline

Yoon JH, Maddock RJ, Rokem A, Silver MA, Minzenberg MJ, Ragland JD, Carter CS (2010) GABA concentration is reduced in visual cortex in schizophrenia and correlates with orientation-specific surround suppression. J Neurosci 30:3777-3781. CrossRef Medline

Yoshor D, Bosking WH, Ghose GM, Maunsell JH (2007) Receptive fields in human visual cortex mapped with surface electrodes. Cereb Cortex 17: 2293-2302. CrossRef Medline

Zenger-Landolt B, Heeger DJ (2003) Response suppression in vl agrees with psychophysics of surround masking. J Neurosci 23:6884-6893. CrossRef Medline

Zuiderbaan W, Harvey BM, Dumoulin SO (2012) Modeling center-surround configurations in population receptive fields using fMRI. J Vis 12:10. CrossRef Medline 